\title{
INFLUÊNCIA DA TEMPERATURA E DO TEMPO DE ARMAZENAMENTO SOBRE AMOSTRAS DE SORO E PLASMA CANINOS NA ANÁLISE DA ENZIMA ALANINA AMINOTRANSFERASE (ALT)
}

\section{EFFECT OF TEMPERATURE AND STORAGE TIME ON CANINE SERUM AND PLASMA SAMPLES IN THE ANALYSIS OF ENZYME ALANINE AMINOTRANSFERASE (ALT)}

\author{
Érica Pereira da Silva ${ }^{1^{*}}$ \\ Mariana de Medeiros Torres ${ }^{1}$ \\ Thalita Priscila Peres Seabra da Cruz ${ }^{1}$ \\ Adriane Jorge Mendonça ${ }^{1}$ \\ ${ }^{1}$ Universidade Federal de Mato Grosso, Cuiabá, MT, Brasil. \\ *Autora para correspondência - erica.p.silva@hotmail.com
}

\section{Resumo}

Este trabalho teve como objetivo avaliar a influência do tempo e da temperatura de armazenamento sobre os valores das dosagens bioquímicas de ALT em 60 amostras de soro e plasma de cães, divididas em dois grupos: GR (grupo refrigerado, a $5{ }^{\circ} \mathrm{C}$ ) e GC (grupo congelado, a $-20{ }^{\circ} \mathrm{C}$ ), por até 96 horas analisadas em seis tempos e até 60 dias, analisadas em cinco tempos, respectivamente. $\mathrm{O}$ estudo mostrou que o congelamento e a refrigeração não provocaram variações entre as amostras $(\mathrm{p}<0,005)$. Os dados obtidos nas dosagens bioquímicas revelaram que o soro e o plasma com EDTA mantiveramse próximos dos valores basais, ou seja, não se alteraram significantemente ao longo do tempo de conservação e nas diferentes temperaturas estudadas.

Palavras-chave: Alanina aminotransferase; conservação; plasma; soro.

\begin{abstract}
This study aimed to evaluate the effect of time and storage temperature on the values of ALT biochemical measurements in 60 samples of serum and plasma of dogs divided into two groups: RG (refrigerated group, at $5{ }^{\circ} \mathrm{C}$ ) and FG (frozen group, at $-20^{\circ} \mathrm{C}$ ) for 96 hours analyzed at six moments and up to 60 days examined at five moments, respectively. The study showed that the effect of freezing and cooling caused no variation between the samples $(p<0.005)$. The data showed that the biochemical serum and EDTA plasma remained near baseline, i.e., they did not change significantly over time and at different storage temperatures.
\end{abstract}

Keywords: Alanine aminotransferase; conservation; plasma; serum. 


\section{Introdução}

A alanina aminotransferase (ALT) é uma enzima citoplasmática encontrada em grande concentração no fígado e, em menor quantidade, nos rins, músculos e eritrócitos. Por essa razão é considerada como um bom indicador de hepatopatias agudas em cães, principalmente doenças hepatocelulares, necrose, obstrução biliar e intoxicações ${ }^{(1,2)}$. A dosagem da ALT é utilizada tanto na rotina de laboratórios veterinários quanto em pesquisas e, neste caso, as amostras comumente são armazenadas por períodos que variam de dias a meses para posterior análise ${ }^{(3,4)}$.

Há uma variação considerável entre enzimas e até entre espécies sobre a estabilidade enzimática no soro ou no plasma ${ }^{(2)}$. Portanto, a padronização de métodos para o manuseio e armazenamento de amostras permite uma menor interferência na concentração dos metabólitos ${ }^{(5)}$. O presente estudo avaliou a influência do tempo e da temperatura de armazenamento sobre os valores das dosagens de ALT em amostras de soro e plasma de cães.

\section{Material e Métodos}

As amostras de sangue foram provenientes de 60 cães adultos, sem distinção entre machos e fêmeas, da rotina do Laboratório de Patologia Clínica Veterinária (LPCV), do Hospital Veterinário da Universidade Federal de Mato Grosso (HOVET - UFMT). As amostras foram obtidas por punção de veia jugular, sendo $3 \mathrm{~mL}$ com EDTA (plasma) e $5 \mathrm{~mL}$ sem EDTA (soro), centrifugadas a 2183 giros/min, por 5 minutos, e separadas em microtubos para posterior análise e armazenamento.

Este projeto foi aprovado pelo Comitê de Ética no Uso de Animais (CEUA) da UFMT sob $n^{\circ}$ 23108.060146/13-7 e encontra-se de acordo com os Princípios Éticos na Experimentação Animal, adotados pelo Conselho Nacional de Controle de Experimentação Animal (CONCEA).

Para a realização das análises bioquímicas foram formados dois grupos: o refrigerado (GR) e o congelado (GC). O GR foi constituído por amostras armazenadas à temperatura de aproximadamente $5{ }^{\circ} \mathrm{C}$, até o final da última dosagem. Foram realizadas seis análises distribuídas da seguinte forma: basal (T1), realizada logo após a coleta, seis horas (T2), 24 horas (T3), 48 horas (T4), 72 horas (T5) e 96 horas (T6) após a coleta. No GC, as amostras de soro e plasma foram separadas em cinco alíquotas, congeladas à temperatura de $-20{ }^{\circ} \mathrm{C}$ e descongeladas somente no momento de cada dosagem. Foram realizadas cinco análises de cada amostra durante o período de até 60 dias, nos seguintes intervalos de tempo: basal (T1), logo após a coleta, com sete dias (T2), 14 dias (T3), 30 dias (T4) e 60 dias (T5) após a coleta.

As amostras foram submetidas à análise pelo método cinético, com a utilização do kit comercial (ALT - PP Gold Analisa $\left.{ }^{\circledR}\right)$, conforme instruções do fabricante, em analisador bioquímico semiautomático (SB-190 Celm ${ }^{\circledR}$ ), por meio de metodologia enzimático-colorimétrica.

Os dados foram analisados com o auxílio do programa computacional GraphPad Prism, pelo método One Way ANOVA. 


\section{Resultados}

Não ocorreram alterações significantes nas amostras de soro e plasma, tanto refrigeradas quanto congeladas, durante os tempos analisados.

Na Tabela 1 estão apresentados os valores médios bioquímicos para o instante basal T1 (análise controle) e tempos T2, T3, T4, T5 e T6 de refrigeração a $5{ }^{\circ} \mathrm{C}$ para as amostras aliquotadas, tanto de soro quanto de plasma. Na Tabela 2 encontram-se os valores médios também para o instante basal T1 (análise controle) e tempos T2, T3, T4 e T5 de congelamento a $-20^{\circ} \mathrm{C}$ para soro e plasma.

Analisando-se isoladamente as amostras de soro dentro de cada grupo, observou-se que entre as amostras refrigeradas e congeladas não houve diferença estatística entre os tempos avaliados. O mesmo foi observado para as amostras de plasma em ambas as condições e tempos de armazenamento.

Comparando-se os dois grupos (GC e GR), o efeito do congelamento e da refrigeração não provocou variação entre as amostras conforme detalhado nas Tabelas 1 e 2.

Tabela 1. Valores de ALT (UL/L) no plasma, com EDTA, e no soro sanguíneo de cães mantidos sob refrigeração $\left(5^{\circ} \mathrm{C}\right)$ nos diferentes tempos de avaliação

\begin{tabular}{llc}
\hline \multirow{2}{*}{ Tempo (horas) } & \multicolumn{2}{c}{ GR } \\
\cline { 2 - 3 } & Soro & Plasma \\
\hline Basal (T1) & $54,10 \mathrm{a}$ & $51,87 \mathrm{a}$ \\
$06(\mathrm{~T} 2)$ & $54,97 \mathrm{a}$ & $53,00 \mathrm{a}$ \\
$24(\mathrm{~T} 3)$ & $56,77 \mathrm{a}$ & $54,00 \mathrm{a}$ \\
$48(\mathrm{~T} 4)$ & $56,30 \mathrm{a}$ & $54,90 \mathrm{a}$ \\
$72(\mathrm{~T} 5)$ & $59,57 \mathrm{a}$ & $56,77 \mathrm{a}$ \\
$96(\mathrm{~T} 6)$ & $59,50 \mathrm{a}$ & $56,63 \mathrm{a}$ \\
\hline
\end{tabular}

Médias seguidas de mesma letra na coluna não diferem entre si ao nivel de $5 \%$ de significância.

Tabela 2. Valores de ALT (UI/L) no plasma, com EDTA, e no soro sanguíneo de cães, mantidos sob congelamento $\left(-20^{\circ} \mathrm{C}\right)$ nos diferentes tempos de avaliação

\begin{tabular}{lll}
\hline Tempo (dias) & \multicolumn{2}{c}{ GC } \\
\cline { 2 - 3 } & Soro & Plasma \\
\hline Basal (T1) & $66,37 \mathrm{a}$ & $66,63 \mathrm{a}$ \\
07 (T2) & $68,37 \mathrm{a}$ & $68,40 \mathrm{a}$ \\
15 (T3) & $68,60 \mathrm{a}$ & $69,97 \mathrm{a}$ \\
30 (T4) & $65,47 \mathrm{a}$ & $67,70 \mathrm{a}$ \\
60 (T5) & $68,03 \mathrm{a}$ & $71,90 \mathrm{a}$ \\
\hline
\end{tabular}

Médias seguidas de mesma letra na coluna não diferem entre si ao nível de $5 \%$ de significância. 


\section{Discussão}

A estabilidade pré-analítica depende de vários fatores, incluindo-se temperatura, manuseio correto da amostra e tempo, sendo este o fator que causa maior impacto. A estabilidade de uma amostra pode ser comprometida na presença de distúrbios específicos, sendo assim, o tempo máximo de estabilidade de uma amostra deve ser o que permite $95 \%$ de estabilidade de seus componentes ${ }^{(6)}$. Por esse motivo, a coleta foi feita por punção jugular, com soro e plasma imediatamente separados e armazenados.

Os resultados obtidos permitem afirmar que a atividade de ALT, tanto no soro quanto no plasma, manteve-se estável ao longo dos períodos de estocagem por refrigeração. Resultados semelhantes foram observados por Doretto ${ }^{(7)}$, que constatou estabilidade deste mesmo parâmetro por 90 dias em amostras de soro bovino armazenadas a $5{ }^{\circ} \mathrm{C}$, enquanto Jones ${ }^{(8)}$ relatou estabilidade da enzima na mesma espécie por três dias a $4{ }^{\circ} \mathrm{C}$.

No processo de congelamento, as amostras de ALT em soro e plasma também apresentaram estabilidade durante os tempos estabelecidos no estudo, diferente dos resultados obtidos por Jones ${ }^{(8)}$, que relatou atividade de ALT em soro e plasma a $-20^{\circ} \mathrm{C}$ por apenas 42 dias. Entretanto, Thorensen ${ }^{(9)}$, que trabalhou com armazenamento de soro canino a $-20^{\circ} \mathrm{C}$ e $-70^{\circ} \mathrm{C}$, demonstrou que a ALT mantevese estável durante um período maior, por 90 e 240 dias, respectivamente.

O aumento não significativo proporcional ao tempo de armazenamento em amostras refrigeradas observado no estudo pode ser justificado pela variação intrínseca de cada animal, conforme observado por Ruaux et al. ${ }^{(10)}$, que descreveram uma baixa variação na atividade de ALT em amostras coletadas no mesmo animal. Além disso, os autores relataram que a temperatura de estocagem pode interferir na amostra, reduzindo sua variabilidade.

Nas amostras congeladas, verificou-se uma pequena oscilação, de forma não significante, em relação aos tempos analisados. Isso pode ser explicado também pela variação intrínseca individual, além da diferença de volumes no processo de pipetagem das amostras durante os tempos analisados, como relatou Lemgruber ${ }^{(11)}$.

De acordo com os resultados apresentados, é possível dizer que as amostras do grupo GC não sofreram com o processo de congelamento e descongelamento, discordando de $\operatorname{Kramer}^{(12)}$, que relatou ser a ALT no soro muito susceptível à deterioração durante este processo, podendo perder $60 \%$ de sua atividade original.

Com base nos resultados deste trabalho, assim como na literatura consultada, pode-se afirmar que não existe alteração na atividade enzimática de ALT durante diferentes tempos de estocagem, tanto no soro quanto no plasma.

\section{Conclusão}

Em plasma congelado e em soro refrigerado ocorre um aumento não significativo dos níveis de ALT relacionado ao aumento do tempo de armazenamento. O soro e o plasma com EDTA mantiveram-se próximos dos valores basais, ou seja, não alteraram significativamente ao longo do tempo de 
conservação e nas diferentes temperaturas estudadas, de acordo com as condições corretas de coleta e utilização de material estéril. Pode-se empregar o soro e o plasma congelados por até 60 dias ou refrigerados por até 96 horas sem alteração do analito.

\section{Referências}

1. Diaz González FH, Silva SC, Patologia Clínica Veterinária: Texto Introdutório. Porto Alegre: Universidade Federal do Rio Grande do Sul, 2008. 342 p.

2. Stockham SL, Scott MA, Fundamentos de Patologia Clínica Veterinária. 2. ed. Rio de Janeiro: Guanabara Koogan, 744.p. 2011.

3. Devanapalli B, Bermingham MA, Mahajan D, Effect of long-term storage at $-80^{\circ} \mathrm{C}$ on the various lipid parameters in stored plasma samples. Clinica Chimica Acta, Charlottesville, 2002;3(322):179-181.

4.Ehsani A, Afshari A, Bahadori H, Mohri M, Seifi HÁ, Serum constituents analyses in dairy cows: efects of duration and temperature of the storage of clotted blood. Research in Veterinary Science, Bridgwater, 2008:85(3): 473-475.

5. Spinelli MO, Cruz RJ, Godoy CMSC, Motta MC, Efeito da temperatura e tempo no armazenamento de metabólitos no plasma de ratos Wistar recém desmamados. ISSN2238-1589. RESBCAL, São Paulo, 2012;1(4):317-321.

6. SOCIEDADE BRASILEIRA DE PATOLOGIA CLÍNICA, Coleta de Sangue Venoso. Ed. Barueri, SP. Minha Editora, 74.p. 2005.

7. Doretto JS, Influência do tempo e da temperatura de estocagem sobre a estabilidade de alguns constituintes do soro sanguíneo de bovinos. 1996. Dissertação (Mestrado em Patologia Animal). Faculdade de Ciências Agrárias e Veterinárias, Universidade Estadual Paulista, Jaboticabal.

8. Jones DG, Stability and Storage Characteristics of Enzymes in Cattle Blood. Research in Veterinary Science, 1985;38(301-306).

9. Thorensen SI, Tverdal A, Havre G, Morberg H, Effects of Storage and Freezing Temperature on Clinical Chemical Parameters from Canine Serum and Heparinized Plasma. Veterinary Clinical Pathology, Norway, 1995;24(4):129-33.

10. Ruaux CG, Carney PC, Suchodolski JS, Steiner JM, Estimates of biological variation in routinely measured biochemical analytes in clinically healthy dogs. Veterinary Clinical Pathology. 2012; 41(4):541-547.

11. Lemgruber APM, Presgrave OAF, Presgrave RF, Alves EM, Silva RS, Gimenes I. et al. Influencia do erro de micropipetas na dosagem espectrofotometrica do ensaio de endotoxina bacteriana (LAL cromogenico) aplicavel a produtos sujeitos a Vigilancia Sanitaria. Rev Inst Adolfo Lutz. Sao Paulo, 2011;70(3):368-72.

12. Kramer JW, Hoffmann WE, Clinical enzymology. In: Kaneko JJ, Harvey JW, Bruss ML, eds. Clinical Biochemistry of Domestic Animals, 5th edition, 303-325. San Diego: Academic, 1997. 